\title{
Brain functional integration: an epidemiologic study on stress-producing dissociative phenomena
}

This article was published in the following Dove Press journal:

Neuropsychiatric Disease and Treatment

\section{Raffaele Sperandeo ${ }^{1,2, *}$ \\ Vincenzo Monda ${ }^{3, *}$ \\ Giovanni Messina ${ }^{4}$ \\ Marco Carotenuto ${ }^{5}$ \\ Nelson Mauro Maldonato ${ }^{1,2}$ \\ Enrico Moretto ${ }^{1,2}$ \\ Elena Leone ${ }^{1,2}$ \\ Vincenzo De Luca ${ }^{6}$ \\ Marcellino Monda ${ }^{3}$ \\ Antonietta Messina ${ }^{3}$}

'Department of Human Sciences, Università Della, Basilicata, ${ }^{2}$ School of Integrated Gestaltic Psychotherapy,

Torre Annunziata, ${ }^{3}$ Department of

Experimental Medicine, Section

of Human Physiology and Unit

of Dietetic and Sport Medicine,

Università degli Studi della Campania

“Luigi Vanvitelli”, Naples, ${ }^{4}$ Department

of Clinical and Experimental

Medicine, University of Foggia, Foggia,

${ }^{5}$ Department of Mental Health,

Physical and Preventive Medicine,

Clinic of Child and Adolescent

Neuropsychiatry, Università degli

Studi della Campania "Luigi Vanvitelli",

Naples, Italy; ${ }^{6}$ Department of

Psychiatry, University of Toronto,

Toronto, Canada

*These authors contributed equally to this work
Correspondence: Giovanni Messina Department of Clinical and Experimental Medicine, University of Foggia, Via L Pinto, 7 I I 22 Foggia, Italy Email giovanni.messina@unifg.it

\begin{abstract}
Dissociative phenomena are common among psychiatric patients; the presence of these symptoms can worsen the prognosis, increasing the severity of their clinical conditions and exposing them to increased risk of suicidal behavior. Personality disorders as long duration stressful experiences may support the development of dissociative phenomena. In 933 psychiatric outpatients consecutively recruited, presence of dissociative phenomena was identified with the Dissociative Experience Scale (DES). Dissociative phenomena were significantly more severe in the group of people with mental disorders and/or personality disorders. All psychopathologic traits detected with the symptom checklist-90-revised had a significant correlation with the total score on the DES. Using total DES score as the dependent variable, a linear regression model was constructed. Mental and personality disorders which were associated with greater severity of dissociative phenomena on analysis of variance were included as predictors; scores from the nine scales of symptom checklist-90-revised, significantly correlated to total DES score, were used as covariates. The model consisted of seven explanatory variables (four factors and three covariates) explaining $82 \%$ of variance. The four significant factors were the presence of borderline and narcissistic personality disorder, substance abuse disorders and psychotic disorders. Significant covariates were psychopathologic traits of anger, psychoticism and obsessiveness. This study, confirming Janet's theory, explains that, mental disorders and psychopathologic experiences of patients can configure the chronic stress condition that produces functional damage to the adaptive executive system. The symptoms of dissociative depersonalization/derealization and dissociative amnesia can be explained, in large part, through their current and previous psychopathologic experiences.
\end{abstract}

Keywords: mental disorders, personality disorders, amnesia, depersonalization/derealization

\section{Background}

Diagnostic and Statistical Manual of Mental Disorders, fifth edition (DSM-5) and International Statistical Classification of Diseases and Related Health Problems (ICD-10) provide an unsatisfactory description for dissociative disorders (DDs). Specifically, DSM-5 classifies DD in an independent nosographic category among somatoform disorders and symptoms related to stress and trauma, ${ }^{1}$ while the ICD-10 codes DD within conversion disorders. ${ }^{2}$

In general, differences between DSM-5 and ICD-10 are not many, both identifying the core of DDs consists in the loss of consciousness, memory, identity and personal somatic perception integration with a chronic clinical outcome (DSM-5) or with symptoms generally occurring as transient disturbances lasting a few weeks. The conceptual confusion surrounding the term and idea of "dissociation" is remarkable. The term, in fact, is used in clinical literature to express more than 20 different psychic/psychiatric phenomena including both diagnostic categories and adaptive submit your manuscript Dovepress f
Neuropsychiatric Disease and Treatment 2018:14 II-19 (c) hereby accept the Terms. Non-commercial uses of the work are permitted without any further permission from Dove Medical Press Limited, provided the work is properly attributed. For permission for commercial use of this work, please see paragraphs 4.2 and 5 of our Terms (https://www.dovepress.com/terms.php). 
mental processes. ${ }^{3}$ For example, the imaginative absorption, alteration in attentive ability or in consciousness state, typical of religious experiences, are treated as diagnostic categories such as depersonalization, derealization or dissociative amnesia; these phenomena, the origin and development of which are a source of debate among researchers, may have little in common with each other. ${ }^{4}$

Moreover, according to the psychodynamic framework, the concept of dissociation involves and is related to the intrapsychic defenses, emerging as the effect of long-term trauma and/or severe psychologic stress. ${ }^{5}$ In this light, pathologic and adaptive dissociative phenomena may be considered and treated as different entities. ${ }^{6}$ These conceptual and clinical differences are consistent with the diathesis stress model for development of the disease. In other words, as effects of the pressure of adverse/stressful events, the adaptive dissociative phenomena are intensified. In this light, the normal dissociative phenomena would be the phenomenological expression of psychobiological processes occurring in unfavorable conditions. ${ }^{7,8}$

\section{Historical evolution of the dissociation concept}

Since the end of World War II and until a few decades ago, the concept of dissociation has been debated, and only after the DSM-III coding of the diagnosis of posttraumatic stress disorder (PTSD), the interest for dissociative phenomena has renewed as an effect of traumatic/stressful event. On the other hand, the strong influence of Freudian psychoanalytic model and the attempt of neo-Kraepelinian paradigm to bring the nosology solely to biologic aspects obscured the classical work of Pierre Janet about dissociation for many years. ${ }^{9}$ The current emergence of a paradigm focused on the traumatic model can be considered the beginning of a new point of view in etiology of mental disorders. ${ }^{10,11}$ Moreover, both DSM-5 and ICD-10 coded Kruschke's description about the DDs based on Janet's theory of "mental désagrégation". 9,10 Janet's conceptualization shows elements of coherence with the connectionist model12,13 based on intrinsic view for mental processes, but it also can be integrated with the parallel computational model. ${ }^{14}$ In the latter model, the integration of mental processes is not conceived as a given condition or a mental state previously established, but given as an individual evolutionary dynamic process in which the integration must be achieved and maintained step by step. Finally, the adaptive executive system involved in integrative processes can stall for lack of "mental energy" resulting from the loss of capacity for integration in brain functioning. ${ }^{12-15}$
For the clinical recognition and identification of DD symptoms in an objective manner, the Dissociative Experience Scale (DES) is often used. DES is a psychometric tool able to detect three different types of dissociative phenomena: 1) imaginative absorption, 2) dissociative amnesia and 3) depersonalization/derealization. ${ }^{16}$

Regarding the imaginative absorption dissociative type, it is generally recognized as a physiologic process not related to an altered mental status, even in its extreme manifestations. On the other hand, the dissociative amnesia and the depersonalization/derealization types are identified properly as dissociative symptoms and specifically coded in DSM-5.

The aims of this study were the following: 1) evaluating the presence and extent of dissociative symptoms experienced by participants (psychiatric outpatients and control healthy subjects); 2) analyzing the relevance of these phenomena in the context of different mental disorders and personality disorders and 3) proposing an explanatory model for the development of dissociative symptoms in subjects suffering from other mental disorders.

\section{Patients and methods Population}

We included 933 (413 males and 520 females) psychiatric outpatients (mean age $34.7 \pm 11.48$ years) consecutively recruited from a private practice office. Regarding the educational level, 65 subjects had completed primary school, 185 had completed junior high school, 505 achieved a high school diploma, 177 were graduates and only 1 participant lacked any qualification. The marital status showed that 43 were separated or divorced, 13 were widowers, 497 subjects were unmarried or single and 341 were currently married. Also, 649 persons were employed in an activity of work or study, 270 were unemployed and 14 were retired.

\section{Psychiatric evaluation}

We evaluated: 1) the presence of mental disorders using the mini international neuropsychiatric interview (MINI) interview ver $5.0 ; 2$ ) the presence of personality disorders using the structured clinical interview for DSM-II (SCID-II) interview; 3) psychopathologic characteristics and clinical severity using the symptom checklist-90-revised (SCL-90-R) test and 4) the presence of dissociative phenomena with the DES.

The psychopathologic and clinical evaluation was performed at the time of access to treatment. All subjects gave their written informed consent before participation. The subjects were informed that the data collected would be used in an anonymous way and respecting the confidentiality rules, in sample statistical surveys. All procedures conformed to the 
directives of the Declaration of Helsinki. This study has been approved by the Azienda Sanitaria (NA3) of Naples.

We excluded trauma/dissociative subtype of PTSD individuals through the MINI clinical interview. Exclusion criteria for the study were a history of head trauma as well as congenital or acquired cognitive deficits. Additionally, patients were excluded if, at the time of first access to treatment, they presented with an acute psychotic or manic episode, a severe depressive episode, a stress-related disorder, a DD or somatic symptom disorder.

\section{Clinical test evaluation}

\section{Mini international neuropsychiatric interview}

MINI is a semi-structured diagnostic assessment scale developed by Sheehan et al, ${ }^{46}$ able to identify the pathologic psychiatric symptoms according to ICD-10 and DSM-IV. The interview modules include 14 Axis I disorders, 1 Axis II disorder, antisocial personality disorder (including its stability over time to the consistency shown in the various personality disorders and its impact on clinical and prognosis) and a module related to suicide risk.

\section{Structured clinical interview for DSM-II}

The SCID-II is used to diagnose the personality disorders, both in categorical terms (present or absent criteria) and quantitative terms. The SCID II consists of 119 items, with dichotomous answers (Yes/No). The first one is a brief overview to identify the action and the usual reports of the subject and allows to verify the capacity for introspection. ${ }^{17,18}$ A score of " 3 " on an item of the SCID-II, provided by the clinician, indicates that there is sufficient evidence that the feature described by the item is "pathologic", "persistent" and "widespread". "Pathology" indicates that the characteristic is outside of the normal variation range; "persistent" refers to both the frequency and the duration (a rating of " 3 " means that the feature was often present during the last 5 years); "widespread" refers to the presence of the characteristic in different contexts at home and at work or in the case of items that affect interpersonal relationships, manifests itself in different relationships. The interview was conducted by five trained researchers who have achieved a high inter-rater reliability $(\mathrm{k}=0.81)$.

\section{Dissociative Experience Scale}

The DES is a self-report instrument for rapid compilation and processing that assesses the presence, quantity and type of dissociative experiences without considering specific diagnosis. It is composed of 28 items arranged on an analog scale, where the scores range from 0 to 100 for each item, and the total score is obtained by averaging the scores. The cut-off value indicating the presence of pathologic dissociation regards scores $\geq 20$ : scores $>20$ are associated, in general, to a DD diagnosis. According to DSM-IV-TR, lower scores are frequently observed both in healthy participants and in psychiatric patients in general. Factor analysis has provided an understanding of the DES structure: for the Italian version, the most frequently employed model has three factors. ${ }^{19}$ According to this model, the DES consists of the following subscales:

- dissociative amnesia, which is concerned with actions to which the subject has no memory (items: $3,4,5,8,11$ );

- absorption and imaginative involvement, which indicates total immersion in an activity to the point of becoming completely unaware of the surrounding environment (items: 2, 14, 15, 17, 18, 20, 24); and

- depersonalization-derealization, or altered perceptions of the self and the environment, such as feeling disconnected from the body, from their thoughts, from their feelings (items: 7, 12, 13, 21, 22, 23, 27, 28).

The DES is a valid and reliable instrument for the measurement of dissociative experiences in both clinical samples and in control groups that reveals a similar factor structure in groups of psychiatric patients and normal subjects. Scores at the dissociative experience scale-total score (DES-TOT) $>20$ are considered indicative of a pathologic condition, but do not have diagnostic value. ${ }^{19-22}$

\section{Self-report symptom inventory (SCL-90)}

The SCL-90 is a self-administered scale for the evaluation of psychiatric symptomatology. The compilation is easy and quite fast, as it requires about 15 minutes. The period assessed by the scale is the week prior to administration. It consists of 90 items representing nine usually frequent clinical dimensions in outpatients:

- somatization: indicates the suffering resulting from the perception of somatic dysfunction;

- obsessive-compulsiveness: expresses the behaviors present in obsessive-compulsive disorder;

- sensitivity: reflects the feelings of personal inadequacy and inferiority;

- depression: reflects a broad spectrum of disorders characteristic of depressive disorder;

- anxiety: expresses symptoms and experiences that are usually associated with significant manifestations of anxiety;

- anger-hostility: indicates thoughts and hostile behaviors;

- phobic anxiety: evaluates symptoms usually observed in anxiety and phobia in agoraphobia;

- paranoid ideation: expresses the paranoid mode of thinking, the basis of the alleged paranoid behavior; and 
- psychoticism: expresses psychotic behavior through indirect indicators.

The test yields the General Symptomatic Index, that is, the ratio between the sum of all the items and the number of the evaluated items (it is an index that measures the severity of the subject's symptoms). The nine dimensions were validated on a large population of patients. ${ }^{23-25}$

\section{Collection and analysis of data}

In the first phase of the study, we evaluated the descriptive statistics of the data: 1) the distribution of dissociative symptoms seen with DES in the sample; 2) the frequency and type of diagnosed mental disorders and 3) the frequency and type of personality disorders diagnosed and sociodemographic characteristics of the subjects. The subgroups of patients with and without clinical disorders, with specific diagnosis of mental illness and personality disorders and specific sociodemographic characteristics were compared with respect to the severity of dissociative symptoms (measured with the total scale and the factors from the DES scales) using the univariate analysis of variance (ANOVA) and the Student's $t$-tests. The age of the subjects and psychopathologic traits measured with SCL-90-R scales were compared to the severity of the DDs using the Spearman's ranking correlation test.

Finally, a logistic regression model was built using as dependent variable the presence of dissociative symptoms as measured by a score $\geq 20$ of the total DES scale (in this way, we transform the continuous the DES-TOT scale in dichotomic variable) and using as factors and covariates mental disorders and personality traits significantly related psychopathologically to greater severity of dissociative symptoms. The statistical analysis was performed using SPSS 19.

\section{Results}

Of the total sample of 933 subjects, 118 presented no mental disorder, 296 had at least one personality disorder and 713 subjects were diagnosed with at least one mental disorder. The mental disorder most frequently detected was major depressive disorder present in 443 participants. The borderline personality disorder was diagnosed in 162 participants and was found to be the most frequent personality disorder, followed by narcissistic personality disorder diagnosed in 102 participants (Table 1).

Participants' age was negatively correlated with the total score of the DES scale (rho $=-0.251 ; p<0.05)$ and the factors "depersonalization/derealization" (rho $=-0.216 ; p<0.05$ ) and "absorption imaginative" (rho $=-0.267 ; p<0.05)$. The "dissociative amnesia" factor, however, did not show any correlation with age (Table 2). In this light, young age seems
Table I Diagnosis number of the psychiatric disorders and personality disorders

\begin{tabular}{ll}
\hline & $\begin{array}{l}\text { Diagnosis } \\
\text { number }\end{array}$ \\
\hline Psychiatric disorders & \\
Major depressive disorder & 443 \\
Dysthymia & 66 \\
Panic disorder & 306 \\
Generalized anxiety disorder & 376 \\
Obsessive-compulsive disorder & 107 \\
Hypomanic episode & 48 \\
Social phobia & 31 \\
Alcohol abuse disorder & 29 \\
Substance abuse disorder & 41 \\
Psychotic disorder & 50 \\
Eating disorder & 24 \\
Personality disorders & \\
Borderline personality disorder & 162 \\
Narcissistic personality disorder & 102 \\
Histrionic personality disorder & 14 \\
Schizotypal personality disorder & 3 \\
Obsessive-compulsive personality disorder & 46 \\
Dependent personality disorder & 13 \\
Avoidant personality disorder & 35 \\
Paranoid personality disorder & 43 \\
\hline
\end{tabular}

to be associated with more severe dissociative symptoms except for amnesic symptoms.

Table 3 shows the comparison between the means of the total scale scores and the three factors of DES for sociodemographic groups (Table 3). Except for the values of the dissociative amnesia scale, all scores were significantly higher among unmarried or celibate participants. No significant differences emerged in the DES scores in relation to academic qualifications and employment.

Table 4 shows the type and distribution of dissociative experiences in the sample. About $10 \%$ presented a pathologic score at the total DES evaluation. Moreover, while the symptoms of depersonalization/derealization and imaginative absorption with a gravity gradient were present in $90 \%$ and $100 \%$ of the participants, respectively, dissociative amnesia was present in only $50 \%$ of subjects (Table 4). Scores on the total DES scale and the three factors' scales were compared in two groups: one composed of persons with mental disorders and/or personality disorders (815 participants) and the other one featuring those without clinically relevant disorders (118 participants). Dissociative symptoms were significantly more severe in the first group than the second group (Table 5). In addition, serious dissociative experiences (DES scores $>20$ ) were also significantly more frequent in the first group (14.47\%) than in the second group (4.23\%; $p<0.001)$. The relationship between dissociative phenomena and psychopathologic dimensions detected by SCL-90-R was analyzed by applying Spearman correlation. 
Table 2 The correlation between age and DES

\begin{tabular}{lllll}
\hline $\begin{array}{l}\text { Spearman's } \\
\text { Rho }\end{array}$ & $\begin{array}{l}\text { Total DES } \\
\text { score }\end{array}$ & $\begin{array}{l}\text { Dissociative } \\
\text { amnesia }\end{array}$ & $\begin{array}{l}\text { Depersonalization/ } \\
\text { derealization }\end{array}$ & $\begin{array}{l}\text { Imaginative } \\
\text { absorption }\end{array}$ \\
\hline Age & $-0.251^{*}$ & -0.096 & $-0.216 *$ & $-0.267 *$ \\
\hline
\end{tabular}

Note: $* p<0.05$.

Abbreviation: DES, Dissociative Experience Scale.

All psychopathologic traits detected with the SCL-90-R had a significant correlation with the total score on the DES scale, with the Spearman index values ranging from a maximum of 0.525 for the "obsessive-compulsive" dimension to a minimum of 0.362 for the "phobic anxiety" dimension (Table 6). The average scores of the total scale of DES were significantly higher in subjects with narcissistic personality disorder and borderline personality disorder, but not in patients with other personality disorders (Table 7). Similarly, subjects affected by major depressive disorder or hypomanic disorder, patients under pharmacologic treatment, patients affected by generalized anxiety disorder or psychotic disorders presented average total DES scores higher than controls $(p<0.001$; Table 8$)$. Moreover, subjects with severe suicidal ideation showed more severe dissociative symptoms.

Using total DES score as a dependent variable, a linear regression model was also constructed. Mental and personality disorders which were found to be associated with greater severity of dissociative phenomena through ANOVA were included as predictors; scores from the nine scales of SCL-90-R, significantly correlated to the total DES score $(p<0.001)$, were used as covariates. The model consisted of seven explanatory variables (four factors and three covariates) explaining $82 \%$ of variance. The four significant factors were the presence of borderline and narcissistic personality disorder, substance abuse disorders and psychotic disorders. Significant covariates were psychopathologic traits of anger, psychoticism and obsessiveness. The presence of at least one of the four disorders in a subject was associated with a 4-fold increase in the severity of dissociative symptoms. Similarly, an increase of only one point in one of the three scales of the SCL-90-R increased the severity of DDs by $30 \%$. The presence of four diagnostic categories and psychopathologic dimensions of the three listed in the model gives an account of about $80 \%$ of the severity of the DDs.

\section{Discussion}

Symptoms of DD are suggested as generated by the psychic mechanism of "separation" (though less intense) even among healthy individuals, as well as in victims of trauma and stressful events, just like in the state of imaginative absorption, mainly considered a nonpathologic phenomenon of nature. Amnestic symptoms, however, generated by the compartmentalization of painful memory contents, are unanimously considered typical pathologic manifestations related to trauma more serious than other dissociative events. ${ }^{26}$ The presence of absorption and depersonalization symptoms even

Table 3 Comparison between the mean of the total scale scores and the three factors of DES for sociodemographic groups

\begin{tabular}{|c|c|c|c|c|c|c|}
\hline DES score & $\begin{array}{l}\text { Sociodemographic } \\
\text { groups }\end{array}$ & $\mathbf{M}$ & SD & SE & $\boldsymbol{F}$ & $p$-value \\
\hline Score to the scale & Marriageable or single & II.79 & 10.91 & 0.52 & 5.01 & 0.00 \\
\hline \multirow[t]{3}{*}{ total of the DES } & Married & 8.38 & 10.38 & 0.61 & & \\
\hline & Separated & 8.71 & 8.38 & 1.33 & & \\
\hline & Widower & 7.53 & 7.59 & 2.29 & & \\
\hline \multirow[t]{4}{*}{ Dissociative amnesia } & Marriageable or single & 23.08 & 42.15 & 2.04 & 0.58 & 0.68 \\
\hline & Married & 19.54 & 40.22 & 2.39 & & \\
\hline & Separated & 22.11 & 34.58 & 5.61 & & \\
\hline & Widower & 10.91 & 22.12 & 6.67 & & \\
\hline \multirow[t]{4}{*}{ Imaginative absorption } & Marriageable or single & 136.12 & 112.92 & 5.51 & 8.46 & 0.00 \\
\hline & Married & 91.40 & 100.29 & 6.05 & & \\
\hline & Separated & 84.72 & 69.34 & 11.56 & & \\
\hline & Widower & 80.00 & 107.70 & 34.06 & & \\
\hline Depersonalization/ & Marriageable or single & 94.03 & 104.65 & 5.16 & 4.49 & 0.00 \\
\hline \multirow[t]{3}{*}{ derealization } & Married & 62.40 & 97.68 & 6.02 & & \\
\hline & Separated & 62.57 & 72.61 & 12.27 & & \\
\hline & Widower & 55.00 & 40.62 & 12.85 & & \\
\hline
\end{tabular}

Abbreviation: DES, Dissociative Experience Scale. 
Table 4 The type and distribution of dissociative experiences in the sample

\begin{tabular}{lllll}
\hline & $\begin{array}{l}\text { Total DES } \\
\text { score }\end{array}$ & $\begin{array}{l}\text { Dissociative } \\
\text { amnesia }\end{array}$ & $\begin{array}{l}\text { Imaginative } \\
\text { absorption }\end{array}$ & $\begin{array}{l}\text { Depersonalization/ } \\
\text { derealization }\end{array}$ \\
\hline $\begin{array}{l}\text { Average } \\
\text { SD }\end{array}$ & 10.97 & 23.48 & 122.36 & 87.26 \\
Number of participants (\%) & 11.06 & 42.93 & 110.64 & 106.12 \\
10 & 1.07 & & & 0.00 \\
20 & 2.14 & 0.00 & 10.00 & 10.00 \\
30 & 3.78 & 0.00 & 30.00 & 20.00 \\
40 & 5.36 & 0.00 & 50.00 & 30.00 \\
50 & 7.50 & 0.00 & 70.00 & 50.00 \\
60 & 10.07 & 0.00 & 90.00 & 70.00 \\
70 & 13.21 & 10.00 & 110.00 & 100.00 \\
80 & 18.21 & 20.00 & 160.00 & 150.00 \\
90 & 24.57 & 40.00 & 202.00 & 230.00 \\
\hline
\end{tabular}

Abbreviation: DES, Dissociative Experience Scale.

among patients without clinically relevant disorders and their higher severity among young people and unmarried or single individuals (who were on average younger than married people in this sample) are linked to the semi-physiologic nature of the detachment mechanism itself. The latter is often considered as a protective factor for the integrity of executive functions, basic systems able to adapt to intense and long-lasting stress, promoting integration, interpersonal cohesion and altruistic attitudes in situations of intense collective emotions. ${ }^{27}$ Conversely, amnesic symptoms may be developed due to a poorly functioning mechanism that seems to be like an extreme maladaptive response, and aimed at

Table 5 The dissociative symptoms

\begin{tabular}{|c|c|c|c|c|}
\hline & $\begin{array}{l}\text { DES score } \\
\text { average }\end{array}$ & SD & $t$ & $p$-value \\
\hline \multicolumn{5}{|l|}{ Total DES scores } \\
\hline $\begin{array}{l}\text { Subjects with } \\
\text { psychiatric disorders }\end{array}$ & 10.97 & 11.06 & 23.21 & $<0.001$ \\
\hline $\begin{array}{l}\text { Subjects without } \\
\text { psychiatric disorders }\end{array}$ & 5.54 & 6.30 & & \\
\hline \multicolumn{5}{|c|}{ Dissociative amnesia score } \\
\hline $\begin{array}{l}\text { Subjects with } \\
\text { psychiatric disorders }\end{array}$ & 23.48 & 42.93 & 12.69 & $<0.001$ \\
\hline $\begin{array}{l}\text { Subjects without } \\
\text { psychiatric disorders }\end{array}$ & 7.88 & 19.39 & & \\
\hline \multicolumn{5}{|c|}{ Imaginative absorption score } \\
\hline $\begin{array}{l}\text { Subjects with } \\
\text { psychiatric disorders }\end{array}$ & 122.36 & 110.64 & 18.88 & $<0.001$ \\
\hline $\begin{array}{l}\text { Subjects without } \\
\text { psychiatric disorders }\end{array}$ & 71.35 & 82.74 & & \\
\hline \multicolumn{5}{|c|}{ Depersonalization-derealization score } \\
\hline $\begin{array}{l}\text { Subjects with } \\
\text { psychiatric disorders }\end{array}$ & 87.26 & 106.12 & 23.93 & $<0.001$ \\
\hline $\begin{array}{l}\text { Subjects without } \\
\text { psychiatric disorders }\end{array}$ & 33.26 & 45.91 & & \\
\hline
\end{tabular}

Abbreviation: DES, Dissociative Experience Scale. protecting an individual's mental integrity from serious and intolerable events. In general, subjects affected by mental or personality disorders or by clinically relevant psychologic symptoms, experience marked and chronic stress. This general feeling of being mentally unstable may be identified as the origin for a high frequency of DDs. ${ }^{28}$ Even the general correlation between DDs and psychopathologic traits and the General Symptomatic Index clinical severity index detected with SCL-90-R seems to confirm the hypothesis that the link between mental illness and dissociation may be considered as generic and based on the marked stressor effects of these pathologies. The positive result of the univariate ANOVA for these two personality disorders (but not for the other personality disorders) suggests the existence of a specific link between these disorders of personality and DDs. In fact, among individuals affected by borderline personality disorder, reports of traumatic events or of long periods of overwhelming stress are common. For many authors, these

Table 6 The correlation between psychopathologic traits and DES

\begin{tabular}{ll}
\hline & Total DES score \\
\hline Somatization & $\rho=0.385 * *$ \\
Obsessive compulsiveness & $\rho=0.525 * *$ \\
Sensitivity & $\rho=0.492 * *$ \\
Depression & $\rho=0.458 * *$ \\
Anxiety & $\rho=0.449 * *$ \\
Anger-hostility & $\rho=0.472 * *$ \\
Phobic anxiety & $\rho=0.362 * *$ \\
Paranoid ideation & $\rho=0.456 * *$ \\
Psychoticism & $\rho=0.506 * *$ \\
GSI & $\rho=0.553 * *$ \\
\hline
\end{tabular}

Note: $* * p<0.01$.

Abbreviations: DES, Dissociative Experience Scale; GSI, general symptomatic index; SCL-90-R, symptom checklist-90-revised. 
Table 7 The average scores of the total DES in subjects with narcissistic personality disorder and borderline personality disorder and in other personality disorders

\begin{tabular}{|c|c|c|c|c|}
\hline & \multirow{2}{*}{$\begin{array}{l}\text { Total DES } \\
\text { score average }\end{array}$} & \multirow[t]{2}{*}{ SD } & \multicolumn{2}{|c|}{ ANOVA } \\
\hline & & & $F$ & $p$-value \\
\hline \multicolumn{5}{|c|}{ Borderline personality disorder } \\
\hline Without & 8.77 & 9.02 & 77.74 & $<0.01$ \\
\hline With & 17.09 & 14.42 & & \\
\hline \multicolumn{5}{|c|}{ Narcissistic personality disorder } \\
\hline Without & 9.46 & 9.98 & 37.17 & $<0.01$ \\
\hline With & 16.61 & 13.63 & & \\
\hline \multicolumn{5}{|c|}{ Histrionic personality disorder } \\
\hline Without & 10.30 & 10.74 & 0.27 & $>0.05$ \\
\hline With & 8.74 & 7.86 & & \\
\hline \multicolumn{5}{|c|}{ Schizotypal personality disorder } \\
\hline Without & 10.25 & $10.6 \mathrm{I}$ & 2.68 & $>0.05$ \\
\hline With & 20.36 & 27.04 & & \\
\hline \multicolumn{5}{|c|}{ Obsessive-compulsive personality disorder } \\
\hline Without & 10.18 & 10.52 & 0.83 & $>0.05$ \\
\hline With & 11.69 & 13.20 & & \\
\hline \multicolumn{5}{|c|}{ Dependent personality disorder } \\
\hline Without & 10.27 & $10.7 \mid$ & 0.12 & $>0.05$ \\
\hline With & 11.33 & 9.20 & & \\
\hline \multicolumn{5}{|c|}{ Avoidant personality disorder } \\
\hline Without & 10.30 & 10.77 & 0.12 & $>0.05$ \\
\hline With & 9.57 & 8.33 & & \\
\hline \multicolumn{5}{|c|}{ Paranoid personality disorder } \\
\hline Without & 10.11 & 10.65 & 3.59 & $>0.05$ \\
\hline With & 13.47 & 10.97 & & \\
\hline
\end{tabular}

data would indicate that borderline personality disorder and DD may share the same pathogenesis (almost partially), or that borderline personality disorder is a disorder dissociative in nature rather than a personality disorder. However, the narcissistic personality disorder does not appear to have attributed to DDs, and the same relationship we found between this personality disorder and DD should be further clarified. The psychodynamic models can provide a good explanatory hypothesis about the relationship between DD,

Table 8 Total Dissociative Experience Scale score in subjects affected by major depressive disorder

\begin{tabular}{|c|c|c|c|c|}
\hline Factors & B & Beta & $t$ & $p$-value \\
\hline Narcissistic personality disorder & 4.200 & 0.092 & 3.853 & $<0.001$ \\
\hline Borderline personality disorder & 2.996 & 0.085 & 3.247 & $<0.001$ \\
\hline Substance abuse disorder & 4.493 & 0.065 & 2.836 & 0.005 \\
\hline Psychotic disorders & 3.663 & 0.058 & 2.523 & 0.012 \\
\hline \multicolumn{5}{|l|}{ Covariates } \\
\hline $\begin{array}{l}\text { Obsessive compulsiveness } \\
\text { (SCL-90-R) }\end{array}$ & 0.338 & 0.373 & 7.079 & $<0.001$ \\
\hline Psychoticism (SCL-90-R) & 0.344 & 0.247 & 4.779 & $<0.001$ \\
\hline Anger/hostility (SCL-90-R) & 0.234 & 0.117 & 3.269 & 0.001 \\
\hline
\end{tabular}

Abbreviation: SCL-90-R, symptom checklist-90-revised.
Axis I disorder and personality disorders. In this framework, both narcissistic disorder and borderline personality disorder are characterized by negative representations of self- and/or objective relationships and by the unconscious effort that patients make to ward off self-devaluing experience and their significant relationships. In this perspective, Gabbard ${ }^{29}$ argued that the narcissist hypervigilant try to maintain their self-esteem by preventing situations of vulnerability, while the borderline individual experiences difficulties in integrating positive and negative views of self and others by creating a division between segregated positive and negative feelings.

Moreover, according to psychodynamic vision, the obsessiveness is based on the "separation of affections" defense mechanism, which can be considered as an emotional desensitization mechanism. Again, according to Gabbard, ${ }^{29}$ the obsessive-compulsive patients defend themselves from these feelings through reactive formation and isolation of affection, as they find rage and addiction as consciously inacceptable concepts. In Henriksen and Nordgaards' view of phenomenological psychopathology, ${ }^{30}$ psychotic disorders are considered as a disorder of the self, and as based on a deficit in awareness of somatosensory experiences, as these processes may involve the same frontal neural network able to disconnect experiences, feeling and consciousness in dissociative phenomena ${ }^{31,33}$ as led and caused also by drugs causing a direct injury to cortico-frontal integration structures. ${ }^{32}$ Finally, anxiety disorders and affective disorders may be linked to DDs through nonspecific stressful effects.

According to Janet, ${ }^{33}$ the integration of the functions of consciousness, memory, somatic perception and sense of personal identity is guaranteed by an efficient degree of mental energy and by adequate psychologic evolution. In other words, an adaptive executive system ensures mental efficiency if it is developed properly over time and is supported by sufficient mental energy. Following traumatic experiences and periods of intense and overwhelming stress for the subject, the functional integrity of the adaptive processes would be maintained by two mechanisms: compartmentalizing painful experiences and reducing somatic-emotional sensitivity. The first of these two mechanisms, which results in amnesia, is effective only if the dissociated contents of consciousness are not excessively broad. If dissociative amnesia is related to a small number of contents, the process can be effective in protecting the person from traumatic memories. In contrast, the second mechanism, resulting in depersonalization/ derealization, assumes pathologic connotations only if intense to interrupt the continuity of conscious experiences. ${ }^{35-39}$ Both dissociative mechanisms are considered as protective, for 
individuals' mental efficiency stops working if other stressful events (eg, affective mental disorders) intervene to subtract energy to the adaptive executive system. In this case, the dissociated memory contents burst in an uncoordinated way into consciousness, and overwhelming emotions, kept in check by desensitization, burst generating intense emotional crisis. These associated phenomena constitute the clinical picture of dissociative identity disorder. ${ }^{39-43}$

\section{Conclusion}

A significant overlap between dissociative phenomena and many mental disorders should not be interpreted as a mere phenomenological overlap, but as a possible latent process that connects these psychopathologic phenomena. ${ }^{28,44,45}$

This study, through the evidence from ANOVA, Spearman's correlation and structure of the regression model, confirms Janet's theory. The central point of the work in question is the idea that mental disorders and psychopathologic experiences of patients can per se configure the chronic overwhelming stress condition that produces functional damage to the adaptive executive system. The sample of the study, in fact, has been selected by excluding subjects with a history of physical and psychologic trauma, suffering from chronic and acute PTSD, as well as somatoform disorders and dissociative identity disorder. In this way, we obtained a sample of subjects in whom the symptoms of dissociative depersonalization/derealization and dissociative amnesia can be explained, in large part, through their current and previous psychopathologic experiences. In these subjects, the disruption in efficiency of the integration network, produced by mental illness, can occur in two ways: a nonspecific type that consists in the subtraction of energy from mental functions and a specific type which can induce in the subject the development of compartmentalization and desensitization mechanisms. The first, as is clear from the results of univariate ANOVA and Spearman's correlation, concerns especially affective disorders, various forms of anxiety, feelings of personal inadequacy, paranoid thoughts and bodily suffering; the second, as is clear from the regression model, covers the narcissistic and borderline personality disorder, the effect of drugs, anger and hostility, and finally psychotic psychopathology and obsessive compulsiveness.

These findings highlight how dissociative phenomena arise not only as a result of traumatic events, but also as a result of the stress induced by some psychic disorders. This appears to be a non-specific reaction to all forms of stressful experiences.

\section{Acknowledgments}

Giovanni Messina and Antonietta Messina are second-degree relatives. Vincenzo Monda and Marcellino Monda are firstdegree relatives.

\section{Author contributions}

All authors contributed toward data analysis, drafting and critically revising the paper and agree to be accountable for all aspects of the work.

\section{Disclosure}

The authors Raffaele Sperandeo, Vincenzo Monda, Giovanni Messina, Marco Carotenuto, Nelson Mauro Maldonato, Enrico Moretto, Elena Leone, Vincenzo De Luca, Marcellino Monda, and Antonietta Messina report no conflicts of interest in this work.

\section{References}

1. Regier DA, Kuhl EA, Kupfer DJ. The DSM-5: Classification and criteria changes. World Psychiatry. 2013;12(2):92-98.

2. Puzyński S. Zaburzenia afektywne w X wersji Miedzynarodowej Klasyfikacji Chorób (ICD-10) [Affective disorders in international classification of disorders ICD-10: classification of mental and behavioral disorders]. Psychiatr Pol. 1992;26(3-4):175-183. Polish.

3. Spiegel D, Loewenstein RJ, Lewis-Fernández R, et al. Dissociative disorders in DSM-5. Depress Anxiety. 2011;28(9):824-852.

4. Putnam FW. Dissociation in children and adolescents: a developmental perspective. Guilford Press. Psychiatr Clin North Am. 1991;14(3): $519-531$.

5. van der Hart O, Brown P, Graafland M. Trauma-induced dissociative amnesia in World War I combat soldiers. Aust N Z J Psychiatry. 1999;33(3):392-398.

6. Waller NG, Ross CA. The prevalence and biometric structure of pathological dissociation in the general population: taxometric and behavior genetic findings. J Abnorm Psychol. 1997;106(4):499-510.

7. Butler LD. Normative dissociation. Psychiatr Clin North Am. 2006; 29(1):45-62.

8. Villano I, Messina A, Valenzano A, et al. Basal forebrain cholinergic system and orexin neurons: effects on attention. Front Behav Neurosci. 2017;31;11:10

9. Bühler KE, Heim G. Etiology, pathogenesis, and therapy according to Pierre Janet concerning conversion disorders and dissociative disorders. Am J Psychother. 2011;65(4):281-309.

10. Kalish ML, Kruschke JK. The role of attention shifts in the categorization of continuous dimensioned stimuli. Psychol Res. 2000; 64(2):105-116.

11. Longden E, Madill A, Waterman MG. Dissociation, trauma, and the role of lived experience: toward a new conceptualization of voice hearing. Psychol Bull. 2012;138(1):28-76.

12. Bugaiska A, Clarys D, Jarry C, et al. The effect of aging in recollective experience: the processing speed and executive functioning hypothesis. Conscious Cogn. 2007;16(4):797-808.

13. Golos M, Jirsa V, Daucé E. Multistability in large scale models of brain activity. PLoS Comput Biol. 2015;11(12):e1004644.

14. McClelland A. Psychological and psychiatric aspects of learning difficulties. Br J Hosp Med. 1986;36(1):35-44.

15. Li D, Spiegel D. A neural network model of dissociative disorders. Psychiatr Ann. 1992;22(3):144-147. 
16. Viggiano A, Chieffi S, Tafuri D, Messina G, Monda M, De Luca B. Laterality of a second player position affects lateral deviation of basketball shooting. J Sports Sci. 2014;32(1):46-52.

17. Maffei C, Fossati A, Agostoni I, et al. Interrater reliability and internal consistency of the structured clinical interview for DSM-IV axis II personality disorders (SCID-II), version 2.0. J Pers Disord. 1997;11(3):279-284.

18. Chieffi S, Messina G, Villano I, et al. Exercise influence on hippocampal function: possible involvement of orexin-A. Front Physiol. 2017;8:85

19. Bernstein EM, Putnam FW. Development, reliability, and validity of a dissociation scale. J Nerv Ment Dis. 1986;174(12):727-735.

20. Carlson EB, Putnam FW. An update on the dissociative experiences scale. Dissociation Prog Dissociative Dis.1993;6:16-27.

21. Ross CA, Ellason JW, Anderson GA. Factor analysis of the dissociative experiences scale (DES) in dissociative identity disorder. Dissociation Progr Dissociative Dis. 1995;8:229-235.

22. Steinberg M, Rounsaville B, Cicchetti D. Detection of dissociative disorders in psychiatric patients by a screening instrument and a structured diagnostic interview. Am J Psychiatry. 1991;148(8):1050-1054.

23. Clark A, Friedman MJ. Factor structure and discriminant validity of the SCL-90 in a veteran psychiatric population. J Pers Assess. 1983;47(4): 396-404.

24. Derrogatis LR, Lipman RS, Covi L. The SCL-90: an outpatient psychiatric rating scale preliminary report. Psychopharmacol Bull. 1973; 9(1):13-28.

25. Dinning WD, Evans RG. Discriminant and convergent validity of the SCL-90 in psychiatric inpatients. J Pers Assess. 1977;41(3):304-310.

26. Spiegel D. Trauma, dissociation, and memory. Ann N Y Acad Sci. 1997; 821:225-237.

27. Ruberto M, Precenzano F, Parisi L, et al. Visuomotor integration skills in children affected by obstructive sleep apnea syndrome: A case-control study. Acta Medica Mediterranea. 2016;32:1659-1663.

28. Sar V, Ross C. Dissociative disorders as a confounding factor in psychiatric research. Psychiatr Clin North Am. 2006;29(1):129-144.

29. Proscenzano F, Ruberto M, Salerno M, et al. Borderline intellectual functioning and parental stress: An italian case-control study. Acta Medica Mediterranea. 2016;32:1762-1765.

30. Henriksen MG, Nordgaard J. Schizophrenia as a disorder of the self. J Psychopathol. 2014;20:435-441.

31. Precenzano F, Ruberto M, Parisi L, et al. ADHD-like symptoms in children affected by obstructive sleep apnea syndrome: A case-control study. Acta Medica Mediterranea. 2016; 32:1756-1759.
32. Koob GF, Le Moal M. Addiction and the brain antireward system. Annu Rev Psychol. 2008;59:29-53.

33. Nakatani Y. [Dissociative disorders: from Janet to DSM-IV]. Seishin Shinkeigaku Zasshi. 2000;102(1):1-12. Japanese.

34. Lanius RA, Vermetten E, Loewenstein RJ, et al. Emotion modulation in PTSD: clinical and neurobiological evidence for a dissociative subtype. Am J Psychiatry. 2010;167(6):640-647.

35. Simeon D, Abugel J. Feeling unreal: Depersonalization Disorder and The Loss of The Self. New York: Oxford University Press; 2006.

36. Bramanti V, Bronzi D, Tomassoni D, et al. Effect of choline-containing phospholipids on transglutaminase activity in primary astroglial cell cultures. Clin Exp Hypertens. 2008;30(8):798-807.

37. Bramanti V, Grasso S, Tomassoni D, et al. Effect of growth factors and steroid hormones on heme oxygenase and cyclin D1 expression in primary astroglial cell cultures. J Neurosci Res. 2015;93(3):521-529.

38. Bramanti V, Tomassoni D, Grasso S, et al. Cholinergic precursors modulate the expression of heme oxigenase-1, p21 during astroglial cell proliferation and differentiation in culture. Neurochem Res. 2012; 37(12):2795-2804.

39. Fung HW. The phenomenon of pathological Dissociation in the Ancient Chinese Medicine Literature. J Trauma Dissociation. 2017;10:1-13.

40. Francavilla G, Abrignani MG, Braschi A, et al. Physical exercise and sport activities in patients with and without coronary heart disease. Monaldi Arch. Chest Dis. 2007;68(2):87-95.

41. Francavilla VC, Abricnani M, Braschi A, Francavilla VC. Utility of QT dispersion in sports medicine. Medicina Dello Sport. 2008;61(4): $477-485$.

42. Merckelbach H, Boskovic I, Pesy D, Dalsklev M, Lynn SJ. Symptom overreporting and dissociative experiences: a qualitative review. Conscious Cogn. 2017;49:132-144.

43. Laddis A, Dell PF, Korzekwa M. Comparing the symptoms and mechanisms of "dissociation" in dissociative identity disorder and borderline personality disorder. J Trauma Dissociation. 2017;18(2):139-173.

44. Sar V. The scope of dissociative disorders: an international perspective. Psychiatr Clin North Am. 2006;29(1):227-244

45. Sar V, Akyüz G, Doğan O. Prevalence of dissociative disorders among women in the general population. Psychiatry Res. 2007;149(1-3): $169-176$.

46. Sheehan DV, Lecrubier Y, Sheehan KH, et al. The Mini-International Neuropsychiatric Interview (MINI): the development and validation of a structured diagnostic psychiatric interview for DSM-IV and ICD-10. J clin psychiatry. 1998;59(Supp1 20):22-33.
Neuropsychiatric Disease and Treatment

\section{Publish your work in this journal}

Neuropsychiatric Disease and Treatment is an international, peerreviewed journal of clinical therapeutics and pharmacology focusing on concise rapid reporting of clinical or pre-clinical studies on a range of neuropsychiatric and neurological disorders. This journa is indexed on PubMed Central, the 'PsycINFO' database and CAS,

\section{Dovepress}

and is the official journal of The International Neuropsychiatric Association (INA). The manuscript management system is completely online and includes a very quick and fair peer-review system, which is all easy to use. Visit http://www.dovepress.com/testimonials.php to read real quotes from published authors. 